\title{
Labor Heterogeneity and Trade Liberalization
}

\author{
Christian Wiermann \\ University of Konstanz
}

\begin{abstract}
This paper identies the decreasing heterogeneity in labor as one of the driving forces ofsecular trade liberalization. A decrease in the sector-specificity of human capital gives rise to a decline of protectionist demands since the workers' stakes in trade policy resemble more and more the social welfare consequences of trade policy. Since the process of labor homogenization appears to be irreversible, we arrive at the conclusion that protectionist trade polices will soon become an obsolescent model.
\end{abstract}

- JEL classifications: D72, F13

- Key words: Labor Heterogeneity, Labor Mobility, Trade Liberalization, Political Economy

\section{Introduction}

The economic development in the second half of the twentieth century is characterized by an unprecedented deepening of trade liberalization and the integration of domestic markets into an economy, which by now encompasses a substantial part of the whole world. Between 1948 and 2000, for example, growth in trade averaged 6 per cent annually and clearly outperformed overall GDP growth of 3.9 per cent per year on average. ${ }^{1}$ At the same time most countries substantially decreased the protection of their domestic economies. Since the establishment of the General Agreement on Tariffs and Trade (GATT)in 1947,

\footnotetext{
*Corresponding address: Department of Economics, University of Konstnz, Box D-138, D-78457 Konstanz, Germany. Tel: +49-7531-88-2137, Fax.: +49-7531-88-3130, E-mail: Wiermann@unikonstanz.de

(C2006-Center for International Economics, Sejong Institution, All Rights Reserved.
} 
tariffs in developed-countries fell in eight rounds of multilateral trade negotiations from an average of 40 per cent on industrial imports to a low of $4 \%$ [Figure 1]. Furthermore, trade benefited from various regional agreements and unilateral decisions to reduce protection.

Even though free trade is desirable on eciency grounds, globalization has redistributional consequences among factor owners. This is liable to create resistance against the reduction of protection, and raises questions about the driving force behind trade liberalization.

There are various explanations for the increase in world trade and the liberalization process. These explanations focus on the decline of transportation costs, the growing speed of communication and the increasing availability of more ecfficient tax raising mechanisms compared to tarffis, especially in developing countries.

Additionally, several reasons which focus on the breakdown of individual resistance against free trade have been identified in the literature. ${ }^{2}$ The emergence of instruments for asset diversication on international capital markets certainly reduces the pressure for protection [Cassing (1996), Feeney and Hillman (2001)].

Figure 1. The development of tariffs and trade between 1950 and 2002 (Sources: tariff Data OECD 1995, Trade Data OECD 2002)

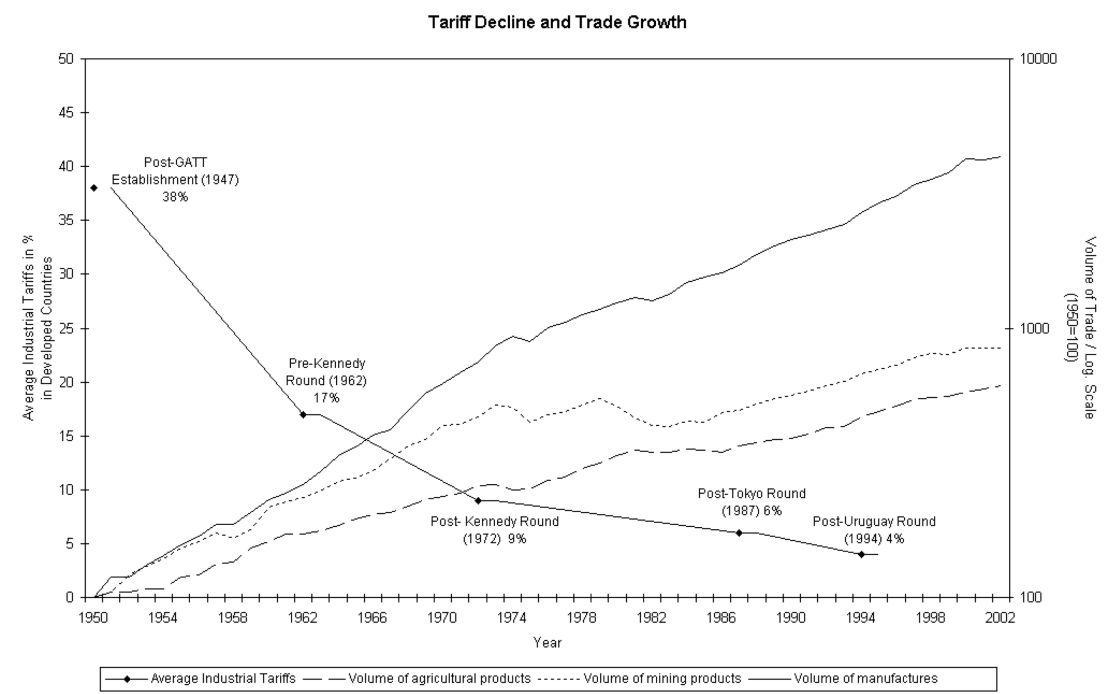

${ }^{1}$ Source: WTO, 2001, p. 7

${ }^{2}$ For a description of the various aspects and characteristics of the liberalization process see the survey by Hillman (2004). 
Capital owners are able to diversify their asset holdings across countries and sectors, and thus do not reap advantages of protectionist policies any more. In a different strand of the literature Grossman and Helpman (1995) investigate under which conditions free-trade-agreements between two countries can arise as an equilibrium outcome, if domestic interest groups approach the government with campaign contributions contingent on the resulting trade policy. Mitra (1999) shows in a model of endogenous lobby formation that free-trade is an equilibrium outcome under the following circumstances. First, if the government is highly welfare oriented and at the same time specific factors are very dispersed across the population, then trade is going to be liberalized. The same is true if the government is very keen on campaign contributions. This fosters the development of a large number of opposing interest groups, and free trade prevails. Hillman and Moser (1996) demonstrate how reciprocity in granting access to foreign markets can lead to liberalization. In their model the authors derive the politically optimal exchange of market access for trading countries. Conditions under which trade liberalization is the outcome of a political contest within two trading nations are studied by Gould and Woodbridge (1998). In their model the exporting firms lobby the foreign government for lower tariffs. They do this because they fear that the importing country might retaliate against tariffs which are levied on their exports, therefore putting harm on the interests of that exporters.

In this paper we explore a determinant of secular trade liberalization that has not been analyzed in the literature. Our explanation is based on the observation that severe structural changes in national labor markets accompanied the trade liberalization process. We argue that the observed decrease in the heterogeneity of labor represents one of the driving forces of secular trade liberalization. As sectorspecific human capital becomes less important, the mobility of workers across sectors increases and individual trade policy preferences become more liberal. ${ }^{3}$

Our explanation of trade liberalization is thus based on two tenets. First, trade policy preferences depend on the degree of intersectoral mobility of workers. If workers are stuck in specific sectors they gain through protection, while the workers employed in other sectors loose. However, if workers have outside options and are able to relocate to the sector with the highest wages, policy preferences

\footnotetext{
${ }^{3}$ This argument is similar to the one put forward by Cassing (1996), who argues that a higher capital mobility leads to increasing asset diversication.

${ }^{4}$ For a detailed analysis of trade policy preferences see for example Magee (1980), Scheve and Slaughter (2001), Mayda and Rodrik (2001), O'Rourke and Sinnott (2001) and Daniels and von der Ruhr (2001).
} 
tend towards free trade. ${ }^{4}$ Second, we argue that the sector-specificity of skills has declined over the last decades. We claim that overall labor became increasingly mobile due to changes on the demand side of the labor market, requiring more flexible and adaptable workers. This development was fostered by rapid technological changes and computerization of nearly all sectors in the economy.The consequence of this process is an ongoing homogenization within the work force which is reflected by an organization of labor towards multitasking and job rotation. Lindbeck and Snower (2000) claim that multi-tasking is the predominant form of labor organization today. Skill-specialization becomes less and less important because modern production processes are increasingly characterized by different tasks. ${ }^{5}$ Lindbeck and Snower identify four factors which have added to this development. First, computerization and technological progress have provided the employees with more informational resources. Second, through this process, the usage of capital per worker has become more versatile.Third, human capital has been growing constantly over the last decades, making the workers able to perform a variety of tasks. Finally, workers have begun to demand a higher variety of tasks in order to better make use of their acquired education. This, following the work of Lindbeck and Snower, led to a breakdown of occupational barriers across sectors. This argument is corroborated by the observed increase in occupational mobility across all skill-groups, which has been reported e.g. by Kambourov and Manovskii (2004) for the US.

The paper is structured as follows. In Section II we describe the economy. We develop a model in which workers are partially mobile, allowing the degree of mobility to gradually rise as the required level of specific skills decreases. ${ }^{6}$ In Section III, we endogenize trade policy. In Section IV we show that a decrease in labor specificity over time gives rise to a decline in protection. Section $5 \mathrm{~V}$ concludes.

\section{The Economy}

Consider a small open economy producing three goods $\mathrm{X}, \mathrm{Y}$ and $\mathrm{Z}$. While $\mathrm{X}$ is a

\footnotetext{
${ }^{5}$ See also Lindbeck and Snower (1999).

${ }^{6}$ Our approach of modelling sector-specificity is similar to Baldwin (1984). In the literature one can nd various other approaches to incomplete factor mobility, where different frictions, which make intersectoral adjustment dfficult, are modelled. Among these are Mussa (1978)[adjustment costs for capital], Karp and Paul (1994), Dehejia (2003)[retraining costs for labor], Dixit and Rob (1994) [constant switching costs between sectors] and Topel (1986)[individual moving costs across sectors].
} 
non-traded numeraire, the goods $\mathrm{Y}$ and $\mathrm{Z}$ are traded internationally. The economy has a comparative advantage in the production of good $\mathrm{Y}$; thus it is a net exporter of good $\mathrm{Y}$ and imports good $Z$. The export sector is supposed to represent a modern growing sector, that attracts workers from the declining import competing sector $Z$. The import sector $Z$ is protected by a tari. ${ }^{7}$ Secular change towards sector $Y$ occurs slowly, because workers have specific skills.

\section{A. Production}

Two kinds of production factors are used. Capital $K_{j}$ is needed in all three sectors $j=X, Y, Z$. Labor $H_{j}$ is only used in sectors $j=Y, Z$. Every unit of labor has benefitted from some sort of specific training, i.e. workers have either specific skills for sector $Y$ or sector $Z$. We denote the number of workers with sector-specific skills in indicates the number of workers with specific skills for the sector $Y(Z)$ in which they are currently employed. $H_{Y}^{Z}\left(H_{Z}^{Y}\right)$ workers are employed in sector $Z(Y)$, but were originally trained in sector $Y(Z)$. The productivity of workers with appropriate, i.e. sector-specific, skills is higher compared to workers who lack the appropriate training. We make the simplifying assumption that workers trained in the advanced sector $\mathrm{Y}$ always earn higher wages in sector $Y$ than in sector $Z$. Thus we can set $H_{Z}^{Y}=0$.

The production structure can be summed up as follows. Sector $X$ produces the numeraire good, using capital $K_{X}$ as the only input factor. The technology is such that one unit of capital is transferred into one unit of output, thus

$$
X=K_{X}
$$

Sector $Y$ is a modern growing sector, which produces the export good using Ytrained labor $H_{Y}^{Y}$, Z-trained labor $H_{Y}^{Z}$, and capital $K_{Y}$ as input factors. $A_{Y}$ is a sector specific technology parameter. The production function has constant returns to scale and suffices the usual assumptions. Thus,

$$
Y=Y\left(H_{Y}^{Y}+\delta H_{Y}^{Z}, K_{Y}, A_{Y}\right)
$$

The parameter $\delta \in[0,1]$ measures the productivity of Z-trained labor as compared to Y-trained labor. If $\delta$ is close to one, specific training is not needed in this sector. Conversely, if $\delta$ is small, workers movingfrom sector $Z$ to sector $Y$ suer from a lack of specific skills and are less productive than the workers $H_{Y}^{Y}$ who are

${ }^{7}$ One can think for example of $Y$ as the IT-sector of the economy, while $\mathrm{Z}$ represents protected industries such as heavy manufacturing or mining. 
endowed with specific skills for sector $Y$.

Sector $\mathrm{Z}$ is the senescent import-competing sector. It also uses labor and capital as input factors. As before, the production function is well behaved. $A_{Z}$ represents a technology parameter:

$$
Z=Z\left(H^{Z}-H_{Y}^{Z}, K_{Z}, A_{Z}\right)
$$

The overall factor endowment of the economy is $K=K_{X}+K_{Y}+K_{Z}$ and $H=H_{Y}$ $+H_{Z}$. Individuals are either workers or capitalists, each supplyingone unit ofthe respective input factor. Thus the overall population size is $N=K+H$. As $\operatorname{good} X$ is the numeraire, its domestic price is $p_{X}=1$. The world market price of the export (import) good is denoted by $p_{Y}^{w}\left(p_{Z}^{w}\right)$. The only trade policy instrument is assumed to be a specific tariffs levied on imports of $Z .^{8}$ Therefore $p_{Z}=p_{Z}^{w}+t_{Z}$.

\section{B. Factor Markets}

Capital is completely mobile across sectors. Because of perfect competition, the fact that $K_{X}$ in sector $X$ is transferred one-to-one into a unit of output and $\operatorname{good} X$ being the numeraire, all capital rewards equal unity. For the different types of labor, the wage rates depend on the distribution of labor across sectors:

$$
\begin{gathered}
w_{Y}^{Y}=p_{Y} Y_{1} \\
w_{Y}^{Z}=\delta p_{Y} Y_{1}=\delta w_{Y}^{Y} \\
w_{Z}^{Z}=\left(p_{Z}^{w}+t_{Z}\right) Z_{1},
\end{gathered}
$$

where the subscript 1 denotes the rst derivative of the respective function. As one can see, the wage rate of the workers who are not especially trained for work in sector $Y$ is always lower by a fraction $\delta$ when compared to the wage rate of the workers with sector specific skills. We assume that the wage rate $w_{Y}^{Y}$ is higher than the wage rate $w_{Z}^{Z} \cdot{ }^{9}$ This reflects the fact that the $Y$-sector is modern, while the Zsector is in decline. From this assumption we also derive that $H_{Z}^{Y}=0$. Only when $\delta$

\footnotetext{
${ }^{8}$ In the following analysis it does not make any substantial different if we use an ad-valorem tariff $p_{Z}=$ $p_{Z}^{w}\left(1+t_{Z}\right)$ or a specific tariff $p_{Z}=p_{Z}^{w}+t_{Z}$.
}

${ }^{9}$ We therefore assume that $A_{Y}$ is sufficiently larger than $A_{Z}$. 
$=1$ are the wage rates equalized as labor under these conditions is completely mobile. $^{10}$

\section{Equilibrium in sector}

When $w_{Y}^{Z}>w_{Z}^{Z}$, protable alternative employment opportunities for $Z$-trained workers arise. Some $Z$-trained workers will then give up their employment in the import-competing industry and move to positions in industry $Y$. A sectoral shift from the ageing to the modern sector takes place. This development comes to an end when the labor market is in equilibrium and the wages of the $Z$-trained workers in sector $Y$ are equal to the wages of the incumbent workers in sector $Z$. The slow factor reallocation process can be described by the following dierential equation

$$
H_{Z}^{Y}\left(H_{Y}^{Z}, t_{Z}\right)=\beta\left[w_{Y}^{Z}-w_{Z}^{Z}\right]=\beta\left[p_{Y} \delta Y_{1}-\left(p_{Z}^{w}+t_{Z}\right) Z_{1}\right]
$$

A positive wage differential leads to an influx of workers into sector $Y$. The parameter $\beta>0$ describes the speed of labor market adjustment. Since

$$
\frac{\partial H_{Y}^{Z}}{\partial H_{Y}^{Z}}=\beta\left[p_{Y} \delta^{2} Y_{2}+\left(p_{Z}^{w}+t_{Z}\right) Z_{2}\right]<0
$$

the labor market adjustment, as portrayed by (2.6), is dynamicallys table. The higher the number of workers that move from sector $Z$ to $Y$, the more the wages in sector $Y$ decrease. At the same time, the wages in sector $Z$ increase, following the changes in the marginal productivity of the workers. The labor market is in equilibrium if $H_{Y}^{Z}\left(H_{Y}^{Z}, t_{Z}\right)=0$ The labor market equilibrium $H_{Y}^{Z}, t_{Z}, \delta$ thus depends on the crucial variables of our model. Furthermore,

$$
\frac{\partial t_{Z}}{\partial \delta}=\frac{p_{Y} Y_{1}}{Z_{1}}>0
$$

The labor market equilibrium locus $H_{Y}^{Z}()=$.0 with $\delta_{0}<\delta_{1}$ has the appearance given in Figure (2). ${ }^{11}$ Equation (2.7) implies that an increase in $\delta$ shifts the locus

\footnotetext{
${ }^{10}$ Note that $\delta=0$ implies that labor is totally sector specific. However, when $\delta=1$ labor is absolutely mobile and factor price equalization occurs and we analyze a Heckscher-Ohlin world. The parameter $\delta$ is therefore not only a measure of the degree of labor heterogeneity and different skill structures, but also a measure of labor mobility.

${ }^{11}$ For our results it does not make a difference, whether the equilibrium locus $H_{Y}^{Z}()=$.0 is convex or concave.
} 
Figure 2. The labor market equilibrium locus

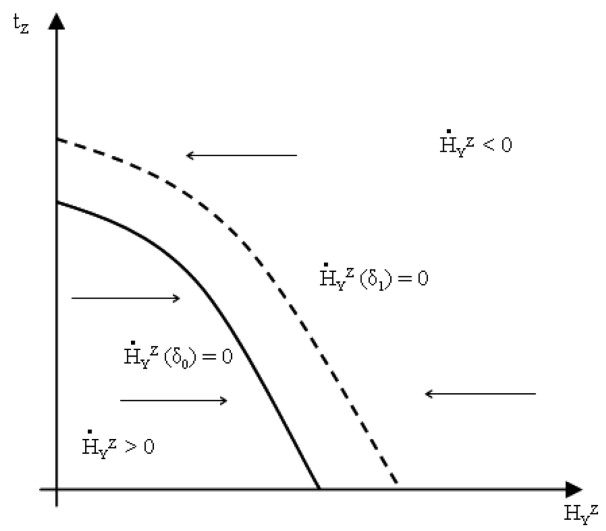

up. The arrows indicate the direction of $H_{Y}^{Z}$ adjustment.

\section{Preferences}

We now turn to the specification of the individual's preferences. They are described by a quasi-linear utility function

$$
U(x, y, z)=x+u(y)+u(z)
$$

The sub-utility functions $u(y)$ and $u(z)$ are quadratic, such that the demand functions $d_{j}$ are linear with respect to the prices. Commodity market equilibrium implies

$$
y=d_{Y}\left(p_{Y}\right)
$$

and

$$
z=d_{Z}\left(p_{Z}^{w}+t_{Z}\right)
$$

Because of the quasi-linearity of the utility function, all income effects are borne by the consumption of good $x$, which is determined by

$$
x=1-p_{Y} Y-\left(p_{Z}^{w}+t_{Z}\right) z,
$$

where $I$ denotes the individual's income. Arise in the income only leads to an increase in the consumption of good $x$. The associated indirect utility function is 


$$
V\left(1, p_{y}, p_{Z}\right)=I+C S_{Y}\left(p_{Y}\right)+C S_{Z}\left(p_{Z}^{w}+t_{Z}\right)
$$

where $C S_{Y}$ and $C S_{Z}$ denote the surplus derived from the consumption of good $Y$ and $Z$, respectively. Imports are denoted by $M=M\left(p_{Z}^{w}+t_{Z}\right)$, and the resulting per capita tariff revenue

$$
T=t_{Z} M\left(p_{Z}^{w}+t_{Z}\right)
$$

is redistributed by the government among all individuals via a lump-sum transfer.

\section{Endogenous Trade Policy}

In this section we describe how the tariff is determined in the political process. The model portrays a representative democracy in which the government maximizes political support by choosing an appropriate tariff rule. This way of modelling endogenous trade policy can be traced back to Stigler (1971) and Peltzman (1976). It was first applied in the context of endogenous trade policy by Hillman (1982) and has been widely used afterwards. ${ }^{12}$ The government grants supernormal profits to certain industries in the economy by choosing a tariff that drives factor rewards in these industries up. This kind of trade policy hurts the consumers via a reduction of consumer's surpluses, and thus yields dissatisfaction with the incumbent government. The resulting tariff is then the solution of a welldefined maximization problem, in which the government trades off additional industry specific support with consumer's dissatisfaction. ${ }^{13}$

In the context of the preceding analysis it is obviously the ageing industry $\mathrm{Z}$ which tries to achieve supernormal profits via a positive tariff. By increasing the tariff, the worker's wages in sector $\mathrm{Z}$ rise, leading to a higher political support for the government. On the other hand social welfare apparently decreases with increasing protection. The resulting political support function therefore has two

\footnotetext{
${ }^{12}$ See for example Cassing and Hillman (1986), Long and Vousden (1991), Devereux and Chen (1999) and Choi (1999) for theoretical renements and Duttand Mitra (2002)for an empirical analysis.

${ }^{13}$ Note, that the channels of support are not modelled. They are beyond the scope of the political support maximization approach that only deals with the supply side's optimal determination of the tariff. However the support channels are most likely in form of votes and campaign contributions as a reward for political patronage.
} 
arguments. Political support increases with higher sector specific profits, and it decreases with lower social welfare. In order to make the government not liable for changes in the world market prices, the arguments of the political support function are formulated as a deviation from world market price levels. This yields

$$
S=S\left[\Pi_{Z}\left(p_{Z}^{w}+t_{Z}\right)-\Pi_{Z}\left(p_{Z}^{w}\right), W\left(p_{Z}^{w}+t_{Z}\right)-W\left(p_{Z}^{w}\right)\right],
$$

where the first argument of $S$ denotes the rents accruing in sector $Z$ and $W(\cdot)$ denotes the social welfare. Since the factor reward for capital $K$ is constant, the rents $\Pi_{Z}$ reduce to the total wages in the $Z$-sector. Therefore

$$
\Pi_{Z}\left(p_{Z}^{w}+t_{Z}\right)=\left(p_{Z}^{w}+t_{Z}\right) Z_{1}\left(H^{Z}-H_{Y}^{Z}\right)
$$

and

$$
\Pi_{Z}\left(p_{Z}^{w}\right)=\left(p_{Z}^{w}\right) Z_{1}\left(H^{Z}-H_{Y}^{Z}\right)
$$

Social welfare is calculated as the sum of the individuals' indirect utilities as given in equation (2.11), i.e. social welfare including tariff revenues plus the cumulated consumer surpluses,

$$
\begin{aligned}
W\left(p_{Z}^{w}+t_{Z}\right)= & X+p_{Y} Y+\left(p_{Z}^{w}+t_{Z}\right) Z+ \\
& N\left[t_{Z} M\left(t_{Z}\right)+C S\left(p_{Y}\right)+C S\left(p_{Z}^{w}+t_{Z}\right)\right]
\end{aligned}
$$

and

$$
\begin{array}{r}
W\left(p_{Z}^{w}\right)=X+p_{Y} Y+\left(p_{Z}^{w}\right) Z+ \\
N\left[C S\left(p_{Y}\right)+C S\left(p_{Z}^{w}\right)\right] .
\end{array}
$$

Substituting expressions (3.2a), (3.2b), (3.3a) and (3.3b) into the political support function (3.1), taking the derivative with respect to $t_{Z}^{*}$, and solving for $t_{Z}^{*}$ yields the political support maximizing tariff:

$$
t_{Z}^{*}=\frac{Z_{1}\left(H^{Z}-H_{Y}^{Z}\right)}{-\frac{\partial M\left(t_{Z}\right)}{\partial t_{Z}} N}>0 .
$$

In the optimum, the marginal gain and the marginal loss between the sector specific interests and the consumer dissatisfaction are equalized. The equilibrium 
tariff level depends on the marginal product of labor $Z_{1}$ in the $Z$ industry, the relative employment share of this sector $\left(H^{Z}-H_{Y}^{Z}\right) / N$, and the reaction of the import demand on tariff changes $\left[\frac{\partial M\left(t_{Z}\right)}{\partial t_{7}}\right]$, which is negative. The resulting tariff varies positively with the size of the sector and negatively with the tariff sensitivity of the imports.

We assume that trade policy cannot be adjusted instantaneously after changes in the underlyingeconomy. ${ }^{14}$ The differential equation portraying the tariff setting behavior of the government has the following appearance:

$$
t_{Z}\left(t_{Z}, H_{Y}^{Z}\right)=\alpha\left[t_{Z}^{*}-t_{Z}\right]=\alpha\left[\frac{Z_{1}\left(H^{Z}-H_{Y}^{Z}\right)}{-\frac{\partial M\left(t_{Z}\right)}{\partial t_{Z}} N}-t_{Z}\right] .
$$

The change in the tariff $t_{Z}$ is proportional to the difference between the equilibrium tariff and the prevailing tariff. The parameter $\alpha>0$ denotes the speed of policy adjustment. Since

$$
\frac{\partial t_{Z}}{\partial t_{Z}}=-\alpha
$$

policy adjustment as modelled by (3.5) is dynamically stable.

In order to derive the curvature of the equilibrium locus $t_{Z}=0$, assume that $Z$ is of Cobb-Douglas type $Z=\left(H^{Z}-H_{Y}^{Z}\right)^{a} K_{Z}^{(1-a)}$. Then the marginal productivity of the workers still employed in sector $Z$ becomes $Z_{1}=\left(H^{Z}-H_{Y}^{Z}\right)^{a-1} K_{Z}^{1-a}$. This yields a tariff equilibrium locus

$$
t_{Z}\left(t_{Z}, H_{Y}^{Z}\right)=\alpha\left[t_{Z}^{*}-t_{Z}\right]=\alpha\left[\frac{a\left(H^{Z}-H_{Y}^{Z}\right)^{a} K_{Z}^{(1-a)}}{-\frac{\partial M\left(t_{Z}\right)}{\partial t_{Z}} N}-t_{Z}\right]
$$

It is straight forward that the equilibrium tariff varies negatively with $H_{Y}^{Z}$. Notice that the tariff equilibrium locus does not depend on the mobility parameter $\delta$, i.e. $\frac{\partial t_{Z}}{\partial \delta}=0$. Figure 3 provides a graphical representation of the tariff equilibrium locus.

\footnotetext{
${ }^{14}$ The diffusion of special interests to the government takes some time. Furthermore, institutional barriers prohibit a continuous accommodation of the directly affected interests.
} 
Figure 3. The tariff equilibrium locus

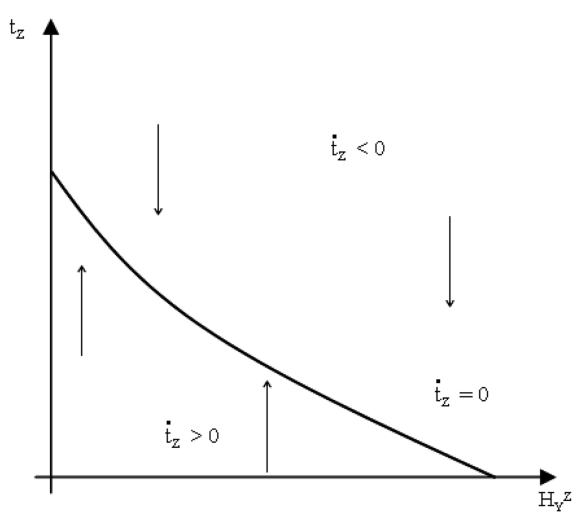

\section{Skill Homogenization and Trade Liberalization}

For the political-economic system to be in a steady state, the labor market $\left(\dot{H}_{Y}^{Z}=0\right)$, as well as the political market for protection $\left(\dot{t}_{Z}=0\right)$, need to be in equilibrium. In order to derive comparative static results with respect to changes in skill homogeneity, we rst linearize the political-economic system around the equilibrium point:

$$
\left[\begin{array}{c}
d \dot{t}_{Z} \\
d \dot{H}_{Y}^{Z}
\end{array}\right]=\underbrace{\left[\begin{array}{cc}
\frac{\partial \dot{t}_{Z}\left(t_{Z}, H_{Y}^{Z}\right)}{\partial t_{Z}} & \frac{\partial \dot{t}_{Z}\left(t_{Z}, H_{Y}^{Z}\right)}{\partial H_{Y}^{Z}} \\
\frac{\partial \dot{H}_{Y}^{Z}\left(t_{Z}, H_{Y}^{Z}\right)}{\partial t_{Z}} & \frac{\partial \dot{t}_{Y}^{Z}\left(t_{Z}, H_{Y}^{Z}\right)}{\partial H_{Y}^{Z}}
\end{array}\right]}_{A}\left[\begin{array}{c}
d t_{Z} \\
d H_{Y}^{Z}
\end{array}\right]+\left[\begin{array}{c}
\frac{\partial \dot{t}_{Z}\left(t_{Z}, H_{Y}^{Z}\right)}{\partial \delta} \\
\frac{\partial \dot{H}_{Y}^{Z}\left(t_{Z}, H_{Y}^{Z}\right)}{\partial \delta}
\end{array}\right]\left[\begin{array}{c}
\partial \delta \\
\partial \delta
\end{array}\right]=0,
$$

where A is the Jacobian matrix given by ${ }^{15}$

$$
A=\left[\begin{array}{ll}
-\alpha & \alpha\left[-\frac{1}{\frac{\partial M\left(t_{Z}\right)}{\partial t_{Z}} N}\right]\left(-Z_{2}\left(H^{Z}-H_{Y}^{Z}\right)-Z_{1}\right) \\
-\beta Z_{1} & \beta\left[p_{Y} \delta^{2} Y_{2}+\left(p_{Z}^{w}+t_{Z}\right) Z_{2}\right]
\end{array}\right]
$$

${ }^{15}$ Notice that $Z_{1}=\frac{\partial z}{\partial\left(H^{Z}-H_{Y}^{Z}\right)}$ and $Z_{2}=\frac{\partial z_{1}}{\partial H_{Y}^{Z}}$. 
We assume the political economy system to be dynamically stable, i.e. $\operatorname{Tr}(\mathrm{A})<0$ and $|\mathrm{A}|>0$. The trace is given by

$$
\operatorname{Tr}(A)=-\alpha+\beta\left[p_{Y} \delta^{2} Y_{2}+\left(p_{Z}^{w}+t_{Z}\right) Z_{2}\right]<0
$$

The determinant of $|\mathrm{A}|$ is

$$
|A|=-\alpha \beta\left[p_{Y} \delta^{2} Y_{2}+\left(p_{Z}^{w}+t_{Z}\right) Z_{2}\right]+\alpha \beta Z_{1}\left[-\frac{1}{\frac{\partial M\left(t_{Z}\right)}{\partial t_{Z}} N}\left(-Z_{2}\left(H^{Z}-H_{Y}^{Z}\right)-Z_{1}\right)\right]
$$

The first term on the RHS of equation (4.4) is positive, the second term is negative. Since we require the system to be dynamically stable, the rst term needs to be larger than the absolute value of the second term. This is consistent when the labor market equilibrium locus in the $H_{Y}^{Z}-t_{Z}$-plane is steeper in absolute terms than the tariff equilibrium locus.

Figure 4 provides a graphical representation of the political-economic equilibrium.An increase in skill homogeneityor labor mobility, i.e. an increase in $\delta$, leads to an outflow of workers out of sector $Z$ and the tariff declines. This induces some more workers to leave the sector until the economy converges to a new steady state. Using Cramer's Rule we can see that

Figure 4. Phase diagram

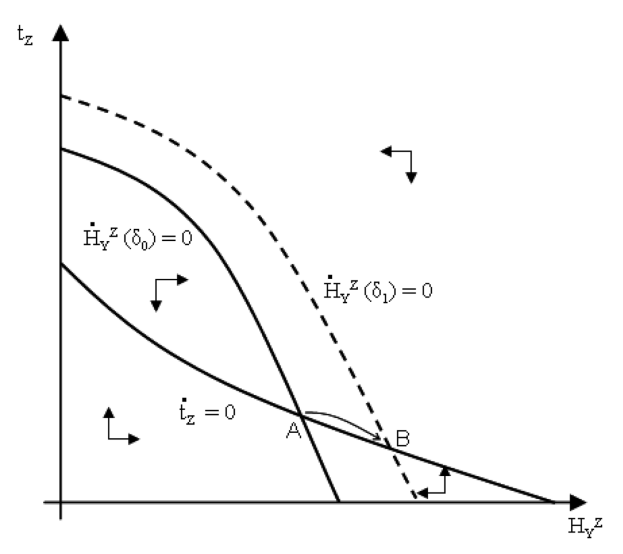




$$
\frac{\partial t_{Z}}{\partial \delta}=\frac{-\frac{\partial \dot{t}_{Z}\left(t_{Z}, H_{Y}^{Z}\right)}{\partial \delta} \frac{\partial \dot{H}_{Y}^{Z}\left(t_{Z}, H_{Y}^{Z}\right)}{\partial H_{Y}^{Z}}+\frac{\partial \dot{H}_{Y}^{Z}\left(t_{Z}, H_{Y}^{Z}\right)}{\partial \delta} \frac{\partial \dot{t}_{Z}\left(t_{Z}, H_{Y}^{Z}\right)}{\partial H_{Y}^{Z}}}{|A|}<0
$$

The denominator is positive by assumption. The rst term in the numerator is zero, as $\frac{\partial \dot{t}_{Z}\left(t_{Z}, H_{Y}^{Z}\right)}{\partial \delta}=0$. The second term in the numerator is negative, rendering the whole expression negative. Therefore we have shown thatan increase in skill homogeneity or labor mobility leads to a decrease in the tariff ofthe import sector and to a relocation of labor into the modern export sector. This increasing homogeneity of the workforce leads to a contraction of the ageing industry and to an expansion ofthe modern export industry, which in turn implies a decline in protection.

\section{Conclusion}

Using a political economy approach to trade policy determination, we have shown that a reduction in the sector-specificity of labor will give rise to secular trade liberalization. Rapid technological changes and computerization of nearly all sectors in the economy, together with a reorganization of production processes towards team-production, job-rotation, and multi-tasking, have over the last 50 years led to a more homogeneous work force and a decline in required specific skills. This development has reduced the stakes of the protectionists' interests in the economy. The intuition behind this is very clear cut. First, the number of workers who benefit from protection decreases, while the number of workers who are in opposition to a tariff, increases. Second, the supernormal profits, originally granted to the workers in the ageing sector, become smaller as more and more employees leave this sector. This reduces the willingness of the government to maintain the initial level of protection. Furthermore, we were able to show how this development leads to sectoral change away from ageing import industries towards modern export industries.

Prominent anti-globalization interest groups and trade unions have complained that the secular trade liberalization process has harmed the low-skilled workers because of their constrained occupational mobility. We strongly disagree with this view. In developed countries, a large share of the low-skilled workers now adays are predominately employed in the tertiary sector, i.e. primarily in low-qualication 
service industries, where the goods are non-traded. ${ }^{16}$ These workers are aected bytrade policy only via their consumer interests. Thus, they should have a strong incentive to promote free trade.

There is reason to believe that the homogenization of labor will continue. As a consequence, the workers' preferences will become more and more liberal. Eventually, workers' and diversied capitalists' interests will be aligned. This would then be the end of trade policy and trade policy analysis.

\section{Acknowledgments}

The author thanks Heinrich W. Ursprung and Jens Südekum for helpful comments and discussions. Financial support of the Deutsche Forschungsgemeinschaft (DFG) through the research project "Heterogeneous Labor: Positive and Normative Aspects of the Skill Structure of Labor" is gratefully acknowledged.

Received 27 December 2004, Accepted 14 September 2005

\section{References}

Baldwin, R. (1984) "Rent-seeking and Trade Policy: An Industry Approach," Weltwirtschaftliches Archiv, 120, 662-677.

Cassing, J. H. (1996) "Protectionist Mutual Funds," European Journal of Political Economy, 12, pp. 1-18.

Cassing, J. H., and A. L. Hillman (1986) "Shifting Comparative Advantage and Senescent Industry Collapse," American Economic Review, 76(3), 516-523.

Choi, J. P. (2001) "Protectionist Response to Import Competition in Declining Industries reconsidered," European Journal of Political Economy, 17, 193-201.

Daniels, J. P., and M. von der Ruhr (2001) "The Determinants of Trade Policy Preferences in Advanced Economies: A Cross-CountryStudy," Unpublished Working Paper.

Dehejia, V. H. (2003) "Will Gradualism Work when Shock Therapy Doesn't?," Economics and Politics, 15(1), 33-59.

Devereux, J., and L. L. Chen (1999) "Growth, the external Terms of Trade and Endogenous Trade Liberalization," Public Choice, 98, 43-57.

Dixit, A., and R. Rob (1994) "Switching Costs and Sectoral Adjustment in General

\footnotetext{
${ }^{16}$ In the European Union (US) 73.6 per cent (73.4 per cent)of all low paid jobs can be found in the service sector, while only 26.4 per cent (26.6 per cent) are in the goods-producing sector (Source: OECD 2001). This is a clear indication for a high number of low skilled workers in the service sector industries.
} 
Equilibrium with Uninsured Risk," Journal of Economic Theory, 62(1), 48-69.

Dutt, P., and D. Mitra (2002) "Political Ideology and Endogenous Trade Policy: An Empirical Investigation," National Bureau of Economic Research, NBER Working Paper 9239.

Feeney, J., and A. L. Hillman (2001a) "Trade Liberalization and Asset Markets," Working Paper, Revised Version.

Gould, D. M., and G. L. Woodbridge (1998) "The Political Economy of Retailiation, Liberalization and Trade Wars," European Journal of Political Economy, 14(1), 115137.

Grossman, G. M., and E. Helpman (1995a) "The Politics of Free Trade Agreements," American Economic Review, 85(4), 667-690.

Hillman, A. L. (1982) "Declining Industries and Political-Support Protectionist Motives," American Economic Review, 72(5), 1180-1187.

(2003) "Trade Liberalization and Globalization," in Encyclopedia of Public Choice, ed. by C. Rowley, and F. Schneider. Kluwer Academic Publishers, Amsterdam.

Hillman, A. L., and P. Moser (1996) "Trade Liberalization as Politically Optimal Exchange of Market Access," in The New Transatlantic Economy, ed. by M. Canzoneri, W. Ethier, and V. Grilli, 295-312. Cambridge University Press.

Kambourov, G., and I. Manovskii (2004) "Occupational Mobility and Wage Inequality," IZA Discussion Paper No. 1189.

Karp, L., and T. Paul (1994) "Phasing In and Phasing Out Protectionism with CostlyAdjustment of Labor," Economic Journal, 104(427), 1379-92.

Lindbeck, A., and D. J. Snower (1999) "Multi-Task Learning and the Reorganization of Work," IZA Discussion Paper No. 39.

(2000) "The Division of Labor and the Market for Organizations," IZA Discussion Paper No. 119.

Long, N. V., and N. Vousden (1991) "Protectionist Responses and Declining Industries," Journal of International Economics, 30, 87-103.

Magee, S. P. (1980) "Three Simple Tests of the Stolper-Samuelson Theorem," in Issues in International Economics, ed. by P. Oppenheimer, 138-153. Oriel Press, Proceedings ofthe Oxford International Symposium in Honor of Harry G. Johnson. London.

Mayda, A. M., and D. Rodrik (2001) "Why are some people (and countries) more protectionist than others?," National Bureau of Economic Research, NBER Working Paper 8461.

Mitra, D. (1999) "Endogenous Lobby Formation and Endogenous Protection: A LongRun Model of Trade Policy Determination," American Economic Review, 89(5), 1116-1134.

Mussa, M. (1978) "Dynamic Adjsutment in the Heckscher-Ohlin Samuelson Model," Journal of Political Economy, 86(5), 775-791.

OECD (2001) “OECD Employment Outlook 2001,” Paris.

O’Rourke, K. H., and R. Sinnott (2001) "The Determinants of Individual Trade Policy Preferences: International Survey Evidence," Unpublished Working Paper. 
Peltzman, S. (1976) "Toward a more general Theory of Regulation," Journal of Law and Economics, 19, 211-240.

Scheve, K. F., and M. J. Slaughter (2001a) "What Determines Individual Trade Preferences," Journal of International Economics, 54, 267-292.

Stigler, G. J. (1971) "The Economic Theory of Regulation," The Bell Journal of Economics and Management Science, 2(1), 3-21.

Topel, R. H. (1986) “Local Labor Markets,” Journal of Political Economy, 94(3, Part 2), 111-143.

WTO (2001) “Statistics on Globalization 2001," Geneva. 